\title{
Can Indeterminacy and Self-Fulfilling Expectations Help Explain International Business Cycles?
}

\author{
Stephen McKnight* \\ El Colegio de México \\ Laura Povoledo ${ }^{\dagger}$ \\ University of the West of England \\ September $2016^{\ddagger}$
}

\begin{abstract}
We introduce equilibrium indeterminacy into a two-country incomplete asset model with imperfect competition and analyze whether self-fulfilling, belief-driven fluctuations (i.e., sunspot shocks) can help resolve the major puzzles of international business cycles. In contrast to the one-good models of the existing literature, we show that sunspot shocks alone cannot replicate the data. Next, we consider a combination of sunspot shocks and technology shocks, and find that the indeterminacy model can now account for the counter-cyclical behavior observed for the terms of trade and real net exports, while simultaneously increasing their volatilities relative to output. The empirical success of the model is due to an unconventional transmission mechanism, whereby the terms of trade appreciates, rather than depreciates, in response to a positive technology shock. This unconventional feature, when combined with sunspot shocks, helps to reconcile the model with the data. However, the major failure of the model is its inability to resolve the Backus-Smith puzzle without a strongly negative cross-country correlation for productivity shocks.
\end{abstract}

JEL Classification: E32; F41; F44

Keywords: Indeterminacy; Sunspots; International Business Cycles; Net Exports; Terms of Trade; Backus-Smith Puzzle.

\footnotetext{
${ }^{*}$ Centro de Estudios Económicos, El Colegio de México, Camino al Ajusco 20, Pedregal de Santa Teresa, Mexico City 10740, Mexico. E-mail: mcknight@colmex.mx.

${ }^{\dagger}$ School of Economics, Bristol Business School, University of the West of England, Coldharbour Lane, Bristol, BS16 1QY, UK. E-mail: laura.povoledo@uwe.ac.uk.

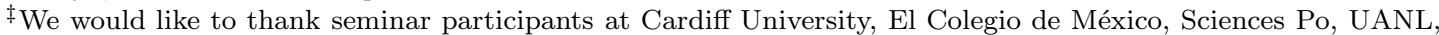
the 2014 annual conference of the Royal Economic Society, and the 2014 Centre for Growth and Business Cycle Research conference held at the University of Manchester for helpful comments and suggestions. We are grateful to Viktoria Hnatkovska for help with the data and to the British Academy Newton Fund for financial assistance (Award Ref: NG160085). The usual disclaimer applies.
} 


\section{Introduction}

Business cycle statistics suggest that the terms of trade and net exports are both counter-cyclical and volatile over the cycle, and the real exchange rate is negatively correlated with relative consumption. ${ }^{1}$ Standard International Real Business Cycle (IRBC) models with a conventional transmission mechanism for productivity shocks struggle to replicate these key properties of the data. ${ }^{2}$ In this paper we investigate whether equilibrium indeterminacy, which allows for self-fulfilling expectations or sunspot shocks, can help account for the observed fluctuations in international relative prices and cross-country trade flows. ${ }^{3}$ This approach has been successful in quantitatively explaining closed-economy business cycles. ${ }^{4}$ We show that indeterminacy can resolve a number of the major puzzles of international business cycles. However, the ability of the model to explain the data rests not only with the inclusion of sunspot-driven belief shocks, but it is also due to the transformation that occurs under indeterminacy to the transmission mechanism of technology shocks.

The model economy we consider is a two-country incomplete asset economy with imperfect competition. In each country, final consumption and investment goods are produced using domestic and foreign intermediate goods. Prices are assumed to be flexible and the real exchange rate deviates from purchasing power parity due to home bias towards domestically-produced intermediate goods. Following Benhabib and Farmer (1994), Schmitt-Grohe (1997), and Benhabib and Wen (2004), indeterminacy is introduced via an increasing returns to scale technology, and consequently the marginal cost schedule of intermediate firms is decreasing in output. By assuming variable capacity utilization, the model can generate indeterminacy for empirically plausible values for the steady-state markup.

Our main findings are summarized as follows. We first show that international business cycle fluctuations driven solely by self-fulfilling expectations cannot replicate the major features of the data. This occurs because the transmission mechanism we uncover for sunspot shocks is analogous to the conventional transmission of technology shocks in standard IRBC models, which is counterfactual. In our model, the aggregate labor demand schedule of each country slopes upwards

\footnotetext{
${ }^{1}$ See, e.g., Backus and Smith (1993), Chari et al. (2002), Corsetti et al. (2008a), Benigno and Thoenissen (2008), Raffo (2008, 2010), and Engel and Wang (2011).

${ }^{2}$ In response to a positive technology shock, the increase in output is associated with a fall in relative prices (i.e. a depreciation of the terms of trade), whereas in the data positive output changes are associated with relative price increases. See Raffo (2010) for an excellent summary of the international business cycle literature.

${ }^{3}$ By indeterminacy we mean that there exists multiple equilibrium paths which converge to the steady state.

${ }^{4}$ See, e.g., Benhabib and Farmer (1994), Farmer and Guo (1994), Schmitt-Grohe (1997, 2000), Benhabib and Wen (2004), and Jaimovich (2007).
} 
in the presence of indeterminacy. A sunspot-induced depreciation of the terms of trade shifts the labor demand schedules in each country in opposite directions, raising domestic output and consumption at the expense of foreign output and consumption. Consequently, the terms of trade are pro-cyclical in the model, and not counter-cyclical as in the data, with insufficient volatility being generated. Moreover, the terms of trade depreciation is associated with an increase in relative consumption in the model, whereas in the data increases in relative consumption are associated with an appreciation of international relative prices. However, we show that a number of the empirical irregularities of the data can be resolved using a combination of sunspot shocks and technology shocks. In this case, the indeterminacy model can generate counter-cyclical behavior for the terms of trade and real net exports, while at the same time, increasing significantly the volatility of international relative prices and cross-country trade flows. This improvement in volatility over the business cycle is not at the cost of reduced volatility of the other aggregate variables, whose standard deviations relative to output are also increased. These findings are shown to be insensitive to the choice of trade price elasticities.

An unconventional transmission mechanism for productivity shocks plays a crucial role in enabling the indeterminacy model to match the main properties of the data. With an upward-sloping aggregate labor demand schedule, technology shocks have two opposing effects on marginal cost. There is a standard effect, where marginal cost is reduced as technology improves, and an additional effect due to increasing returns to scale, where output initially falls below its pre-shock level causing an increase in marginal cost. In the immediate aftermath of a positive productivity shock this second effect dominates, exerting upward pressure on domestic prices, which results in an appreciation of the terms of trade. After a short period of time, the first effect becomes more important as output recovers, exerting downward pressure on domestic prices, and the terms of trade depreciate. The dynamics of the terms of trade are broadly consistent with the empirical findings of Enders et al. (2011) for the U.S. economy. Our results show that this unconventional transmission mechanism can overcome the limitations of standard IRBC models in explaining the dynamics of the terms of trade, and thus, certain important features of the data. This occurs because productivity shocks induce very little co-movement between the terms of trade and output in the short-run.

The major weakness of the indeterminacy model is its inability to resolve the Backus-Smith puzzle. Our estimated model generates a positive correlation between the real exchange rate and 
relative consumption, whereas in the data this correlation is negative. ${ }^{5}$ We show that to resolve this puzzle a strongly negative cross-country correlation for technology shocks is required, which is not typically supported by the literature.

This paper contributes to a small literature that examines the role of indeterminacy and sunspot-driven fluctuations as a possible explanation for international business cycles. Guo and Sturzenegger (1998) and Xiao (2004) introduce sunspot shocks into a two-country, one-good model economy and focus solely on explaining the cross-country correlations observed for consumption and output. This paper extends the endogenous-business-cycle approach to examine several other important features of the data. In two-country, one-good models, positive sunspot shocks stimulate world demand and generate positive cross-country correlations for consumption and output. However, in our two-country, two-good economy the terms of trade can be directly affected by sunspot shocks. ${ }^{6}$ These global shocks result in a reallocation of output between countries, generating negative cross-country correlations for consumption and output.

This paper also contributes to the international real business cycle (IRBC) literature. The recent literature has attempted to resolve the international business cycle puzzles with varying degrees of success. One strand of the literature (e.g. Stockman and Tesar, 1995; Benigno and Thoenissen, 2008) has highlighted the importance of a non-traded goods sector in resolving the Backus-Smith puzzle. Another strand of the IRBC literature (e.g. Boileau, 1999; Engel and Wang, 2011) has emphasized the importance of traded capital goods in increasing the volatility of real net exports and the terms of trade. A third strand (e.g. Heathcote and Perri, 2002; Corsetti et al., 2008a, 2008b; Thoenissen, 2010) has emphasized the role of the trade price elasticity parameter. If this parameter is sufficiently low, this generates a downward-sloping world demand for domestically-traded goods (with respect to the terms of trade) and an unconventional negative international transmission arises where the terms of trade appreciates when domestic production expands. ${ }^{7}$ This paper shows that indeterminacy offers another way to generate an unconventional transmission mechanism for productivity shocks. This unconventional mechanism arises with increasing returns to scale technology and not in terms of restricting the choice of trade price elasticities.

\footnotetext{
${ }^{5}$ This happens because all shocks considered in isolation induce a positive correlation between the real exchange rate and relative consumption.

${ }^{6}$ There is evidence to suggest that terms of trade shocks are an important source of business cycle fluctuations (see, e.g., Mendoza, 1995). In our model, shocks to the terms of trade are due to extrinsic uncertainty.

${ }^{7}$ Thoenissen (2010) shows that a conventional IRBC model can generate enough volatility for the terms of trade and avoid the Backus-Smith puzzle under a negative international transmission calibration. The range of values for the trade elasticity $\theta$ that generate these model properties is very narrow: $0.4113 \leq \theta \leq 0.4678$.
} 
Finally, this paper is also related to the recent studies by Raffo (2010) and Karabarbounis (2014) who also aim to explain the anomalies in international relative prices and quantities via the inclusion of additional sources of exogenous fluctuations. Karabarbounis (2014) introduces a labor wedge into an otherwise standard IRBC model with complete asset markets, whereas Raffo (2010) considers an additional source of technological variation: investment-specific technology shocks. This paper complements these two studies by examining how far indeterminacy and endogenous fluctuations can go in explaining international business cycles.

The remainder of the paper is organized as follows. Section 2 outlines the model economy and Section 3 discusses the calibration of the model and the solution method employed. Section 4 discusses the results obtained from the indeterminacy model, and compares the findings to the determinacy benchmark. Finally, Section 5 briefly concludes.

\section{Model}

We develop a two-country extension of the imperfect competition model studied by Benhabib and Farmer (1994), Schmitt-Grohe (1997), and Benhabib and Wen (2004) for the closed economy. Following Wen (1998), we assume variable capacity utilization which significantly reduces the size of the steady-state markup needed to generate indeterminacy. Within each country there exists a representative agent, two final-good producers, and a continuum of intermediate-good producing firms. Intermediate firms operate under monopolistic competition and use domestic labor and capital as inputs to produce tradeable goods. The competitive final good producers use domestic and imported intermediate goods to produce non-tradeable consumption or investment goods, which are subsequently purchased by the domestic agent. However, final good producers are assumed to have a bias for domestically produced intermediate goods. While the law of one price is assumed to hold for all intermediate goods, with home bias, the real exchange rate deviates from purchasing power parity. The following presents the features of the model for the Home country on the understanding that the Foreign case can be analogously derived. All Foreign country variables are denoted by an asterisk.

\subsection{Final good producers}

In each country, there are two final goods, consumption and investment, which are produced with homogenous of degree one production functions using intermediate goods as the only inputs. The 
Home consumption final good $C_{t}$ is produced by a competitive firm that uses $C_{H, t}$ and $C_{F, t}$ as inputs according to the following CES aggregation technology index:

$$
C_{t}=\left[a^{\frac{1}{\theta}} C_{H, t}^{\frac{\theta-1}{\theta}}+(1-a)^{\frac{1}{\theta}} C_{F, t}^{\frac{\theta-1}{\theta}}\right]^{\frac{\theta}{\theta-1}}
$$

where the constant elasticity of substitution between aggregate Home and Foreign intermediate goods is $\theta>0$ and the relative share of domestic and imported intermediate inputs used in the production process is $0<a<1$. The Home investment final good $I_{t}$ is produced according to the following CES aggregation technology index:

$$
I_{t}=\left[b^{\frac{1}{\rho}} I_{H, t}^{\frac{\rho-1}{\rho}}+(1-b)^{\frac{1}{\rho}} I_{F, t}^{\frac{\rho-1}{\rho}}\right]^{\frac{\rho}{\rho-1}}
$$

where $\rho>0$ and $0<b<1$. The inputs $C_{H, t}, C_{F, t}, I_{H, t}$, and $I_{F, t}$ are defined as the quantity indices of domestic and imported intermediate goods respectively:

$$
\begin{aligned}
C_{H, t} & =\left[\int_{0}^{1} c_{t}(j)^{\frac{\kappa-1}{\kappa}} d j\right]^{\frac{\kappa}{\kappa-1}}, & C_{F, t} & =\left[\int_{0}^{1} c_{t}\left(j^{*}\right)^{\frac{\kappa-1}{\kappa}} d j^{*}\right]^{\frac{\kappa}{\kappa-1}}, \\
I_{H, t} & =\left[\int_{0}^{1} i_{t}(j)^{\frac{\kappa-1}{\kappa}} d j\right]^{\frac{\kappa}{\kappa-1}}, & I_{F, t} & =\left[\int_{0}^{1} i_{t}\left(j^{*}\right)^{\frac{\kappa-1}{\kappa}} d j^{*}\right]^{\frac{\kappa}{\kappa-1}},
\end{aligned}
$$

where the elasticity of substitution across domestic (imported) intermediate goods is $\kappa>1$, and $c_{t}(j), i_{t}(j), c_{t}\left(j^{*}\right), i_{t}\left(j^{*}\right)$ are the respective quantities of the domestic and imported type $j$ and $j^{*}$ intermediate goods. Intermediate firms sell their products to both consumption and investment final-good producers, where it is assumed that the law of one price holds. Cost minimization in final good production yields the demand conditions for Home and Foreign goods:

$$
\begin{aligned}
C_{H, t} & =a\left(\frac{P_{H, t}}{P_{t}}\right)^{-\theta} C_{t}, & C_{F, t} & =(1-a)\left(\frac{P_{F, t}}{P_{t}}\right)^{-\theta} C_{t}, \\
I_{H, t} & =b\left(\frac{P_{H, t}^{I}}{P_{t}^{I}}\right)^{-\rho} I_{t}, & I_{F, t} & =(1-b)\left(\frac{P_{F, t}^{I}}{P_{t}^{I}}\right)^{-\rho} I_{t},
\end{aligned}
$$

and the corresponding aggregate price indices are given by:

$$
P_{t}=\left[a P_{H, t}^{1-\theta}+(1-a) P_{F, t}^{1-\theta}\right]^{\frac{1}{1-\theta}}, \quad P_{t}^{I}=\left[b\left(P_{H, t}^{I}\right)^{1-\rho}+(1-b)\left(P_{F, t}^{I}\right)^{1-\rho}\right]^{\frac{1}{1-\rho}}
$$


where $P_{t}$ is the consumer price index, $P_{t}^{I}$ is the price of investment goods, and $P_{H, t}, P_{H, t}^{I}, P_{F, t}$, $P_{F, t}^{I}$ are the respective price indices of Home and Foreign intermediate goods.

\section{$2.2 \quad$ Intermediate goods producers}

All intermediate firms have access to the same technology. A Home firm of type $j$ has a production technology given by

$$
Y_{t}(j)=Z_{t}\left(u_{t}(j) K_{t}(j)\right)^{\alpha} L_{t}(j)^{\gamma}-\phi, \quad j \in[0,1]
$$

where $K_{t}$ and $L_{t}$ represent capital and labor usage, respectively, $Z_{t}$ is the exogenous level of technology or productivity, and the input share is $\alpha+\gamma \geq 1$. The rate of capacity utilization $u_{t} \in(0,1)$ is endogenously determined. Following Greenwood et al. (1988), it is assumed that the depreciation rate of capital $\delta_{t}$ is higher if it is used more intensively:

$$
\delta_{t}=\frac{1}{\eta} u_{t}^{\eta}
$$

where $\eta>1$. A fixed cost of production $\phi>0$ is also included in the production technology (6). Therefore, regardless of how much output $Y_{t}$ is produced, a proportion $\phi$ of the intermediate good is used up in each period. As in Schmitt-Grohe (1997), allowing for a fixed production cost enables the model to generate zero profits without imposing any restrictions on the size of the steady-state markup. ${ }^{8}$ Given competitive prices of labor and capital, cost-minimization yields:

$$
\begin{gathered}
w_{t}=\gamma m c_{t}(j) Z_{t}\left(u_{t}(j) K_{t}(j)\right)^{\alpha} L_{t}(j)^{\gamma-1}, \\
r r_{t}+\delta_{t}=\alpha m c_{t}(j) Z_{t} u_{t}^{\alpha}(j) K_{t}(j)^{\alpha-1} L_{t}(j)^{\gamma}, \\
u_{t}^{\eta}=\alpha m c_{t}(j) Z_{t} u_{t}^{\alpha}(j) K_{t}(j)^{\alpha-1} L_{t}(j)^{\gamma},
\end{gathered}
$$

where $m c_{t}$ is real marginal cost, $w_{t}$ is the real wage, and $r r_{t}+\delta_{t}$ is the user cost of capital.

Given that the total demand for firm $j$ 's output can be expressed as:

$$
Y_{t}(j)=\left(\frac{p_{t}(j)}{P_{H, t}}\right)^{-\kappa}\left[C_{H, t}+C_{H, t}^{*}\right]+\left(\frac{p_{t}(j)}{P_{H, t}^{I}}\right)^{-\kappa}\left[I_{H, t}+I_{H, t}^{*}\right],
$$

\footnotetext{
${ }^{8}$ As discussed by Rotemberg and Woodford (1996), Schmitt-Grohe (1997), and Jaimovich (2007), positive profits are not observed in the U.S. economy despite the presence of market power.
} 
it follows from the firm's profit maximization problem that the optimal price-setting rule is:

$$
p_{t}(j)=\chi m c_{t}(j) P_{t}
$$

where $\chi \equiv \frac{\kappa}{\kappa-1}$ is the markup.

\subsection{Representative agent}

The representative agent has an expected utility function of the form:

$$
\max E_{0} \sum_{t=0}^{\infty} \beta^{t} U\left(C_{t}, L_{t}\right)
$$

where $C_{t}$ and $L_{t}$ are consumption and work effort, respectively, and the discount factor is $0<\beta<1$. Following Greenwood et al. (1988), we assume that the period utility function is given by:

$$
U\left(C_{t}, L_{t}\right)=\frac{1}{1-\sigma}\left[\left(C_{t}-\frac{\psi}{1+\nu} L_{t}^{1+\nu}\right)^{1-\sigma}-1\right]
$$

where $\sigma>0$ is the relative risk aversion in consumption, $\nu \geq 0$ is the inverse of the Frisch elasticity of labor supply, and $\psi>0$.

The representative agent during period $t$ supplies labor and capital to intermediate-good producing firms, receiving real income from wages $w_{t}$, a rental return on capital $r r_{t}$, and nominal profits from the ownership of domestic intermediate firms $\Pi_{t}$. The agent then uses these resources to purchase the two final goods, dividing purchases between consumption $C_{t}$ and investment $I_{t}$. The purchase of an investment good forms next period's capital according to the law of motion

$$
K_{t+1}=\left(1-\delta_{t}\right) K_{t}+I_{t}
$$

The asset market structure is assumed to be incomplete. The Foreign agent is able to trade two non-state contingent bonds $B_{H, t}^{*}$ and $B_{F, t}^{*}$, whereas the Home agent can only purchase domestic bonds $B_{H, t}$. All bonds are denominated in units of the domestic aggregate consumption index. For the Foreign agent, there is a transaction cost $\Psi$ of adjusting the internationally traded bond $B_{H, t}^{*}$, where it is assumed that $\Psi$ is a positive and differentiable function. ${ }^{9}$ This transaction cost,

\footnotetext{
${ }^{9}$ Following Benigno (2001), we assume that $\Psi=1$ when bond holdings are at their steady-state level and $\Psi$ is positive, differentiable, and strictly decreasing in a neighborhood of the steady state.
} 
which is paid to financial firms, captures the costs of adjusting bond holdings and is sufficient to ensure that bond holdings are stationary. ${ }^{10}$ Consequently, the period budget constraints of the Home and Foreign agent can be expressed in real terms as:

$$
\begin{gathered}
\frac{B_{H, t}}{r_{t}}+C_{t}+\frac{P_{t}^{I}}{P_{t}} I_{t} \leq B_{H, t-1}+\int_{0}^{1} w_{t} L_{t}(j) d j+\int_{0}^{1}\left(r r_{t}+\delta_{t}(j)\right) K_{t}(j) d j+\int_{0}^{1} \Pi_{t}(j) d j+R_{t}, \\
\frac{B_{H, t}^{*}}{Q_{t} r_{t}} \frac{1}{\Psi\left(B_{H, t}^{*}\right)}+\frac{B_{F, t}^{*}}{r_{t}^{*}}+C_{t}^{*}+\frac{P_{t}^{* I}}{P_{t}^{*}} I_{t}^{*} \leq \frac{B_{H, t-1}^{*}}{Q_{t}}+B_{F, t-1}^{*}+\int_{0}^{1} w_{t}^{*} L_{t}^{*}\left(j^{*}\right) d j^{*} \\
+\int_{0}^{1}\left(r r_{t}^{*}+\delta_{t}^{*}\left(j^{*}\right)\right) K_{t}^{*}\left(j^{*}\right) d j^{*}+\int_{0}^{1} \Pi_{t}^{*}\left(j^{*}\right) d j^{*}+R_{t}^{*},
\end{gathered}
$$

where $R_{t}$ and $R_{t}^{*}$ denote rebates from financial firms, $r_{t}$ and $r_{t}^{*}$ are the Home and Foreign (gross) real interest rates, and $Q_{t}$ is the CPI-based real exchange rate.

The Home agent's maximization problem yields:

$$
\begin{gathered}
U_{c}\left(C_{t}, L_{t}\right)=\left(C_{t}-\frac{\psi L_{t}^{1+\nu}}{1+\nu}\right)^{-\sigma}=\lambda_{t}, \\
-\frac{U_{L}\left(C_{t}, L_{t}\right)}{U_{c}\left(C_{t}, L_{t}\right)}=\psi L_{t}^{\nu}=w_{t}, \\
\lambda_{t} \frac{P_{t}^{I}}{P_{t}}=\beta E_{t} \lambda_{t+1}\left[r r_{t+1}+\delta_{t+1}+\left(1-\delta_{t+1}\right) \frac{P_{t+1}^{I}}{P_{t+1}}\right], \\
\beta r_{t} E_{t}\left[\frac{\lambda_{t+1}}{\lambda_{t}}\right]=1,
\end{gathered}
$$

where $\lambda_{t}$ denotes the shadow price of wealth. Analogous conditions to (15)-(18) apply for the Foreign agent, where the following interest-rate parity condition can be derived:

$$
r_{t}=\frac{r_{t}^{*}}{\Psi\left(B_{H, t}^{*}\right)} E_{t}\left[\frac{Q_{t+1}}{Q_{t}}\right]
$$

Optimizing behavior implies that the budget constraints (13) and (14) hold with equality in each period and the appropriate transversality conditions are satisfied.

${ }^{10}$ For an in-depth discussion of the stationary problem of incomplete market, open-economy models, see Schmitt-Grohe and Uribe (2003) and Ghironi (2006). 


\subsection{Market clearing and equilibrium}

We now focus on a symmetric equilibrium where all firms in Home and Foreign set the same price in each period $t$, rent the same amount of capital, and employ the same amount of labor. Consequently, $p_{t}(j)=P_{H, t}=P_{H, t}^{I}$ and the index $j$ can be dropped from all variables. Market clearing in the Home goods market requires:

$$
Y_{t}=C_{H, t}+C_{H, t}^{*}+I_{H, t}+I_{H, t}^{*}
$$

and assuming that the Foreign non-state contingent bond is in zero net supply, bond market clearing requires:

$$
B_{H, t}+B_{H, t}^{*}=0, \quad B_{F, t}^{*}=0 .
$$

The aggregate resource constraint is given by: ${ }^{11}$

$$
C_{t}+\frac{P_{t}^{I}}{P_{t}} I_{t}+\frac{B_{H, t}}{r_{t}}=B_{H, t-1}+\frac{P_{H, t}}{P_{t}} Y_{t}
$$

where

$$
\frac{P_{t}^{I}}{P_{t}}=\frac{\left[b+(1-b) T_{t}^{1-\rho}\right]^{\frac{1}{1-\rho}}}{\left[a+(1-a) T_{t}^{1-\theta}\right]^{\frac{1}{1-\theta}}}, \quad \frac{P_{H, t}}{P_{t}}=\left[a+(1-a) T_{t}^{1-\theta}\right]^{\frac{1}{\theta-1}}
$$

follow from the aggregate price indices (5). The terms of trade $T_{t}$ can be expressed as:

$$
T_{t} \equiv \frac{P_{F, t}}{P_{H, t}}=\frac{\left[a+(1-a) T_{t}^{\theta-1}\right]^{\frac{1}{\theta-1}}}{\left[a+(1-a) T_{t}^{1-\theta}\right]^{\frac{1}{\theta-1}}} Q_{t} .
$$

In what follows, we call an increase (decrease) in the terms of trade, or the real exchange rate, a depreciation (appreciation). Finally, we measure net exports as the difference between exports and imports, divided by total output (all evaluated at steady state prices): ${ }^{12}$

$$
N X_{t}=\frac{C_{H, t}^{*}+I_{H, t}^{*}-\bar{T}\left(C_{F, t}+I_{F, t}\right)}{C_{H, t}+C_{H, t}^{*}+I_{H, t}+I_{H, t}^{*}} .
$$

Equilibrium. An equilibrium for the world economy consists of a set of real prices $r_{t}, r_{t}^{*}, w_{t}$, $w_{t}^{*}, r r_{t}, r r_{t}^{*}, \delta_{t}, \delta_{t}^{*}, m c_{t}, m c_{t}^{*}, \lambda_{t}, \lambda_{t}^{*}$; a set of relative prices $\frac{P_{H, t}}{P_{t}}, \frac{P_{F, t}^{*}}{P_{t}^{*}}, \frac{P_{t}^{I}}{P_{t}}, \frac{P_{t}^{* I}}{P_{t}^{*}}, Q_{t}, T_{t} ;$ a collection

\footnotetext{
${ }^{11}$ By Walras' Law, the aggregate resource constraint of the Foreign country is redundant.

${ }^{12}$ Thus, our measure of net exports is unaffected by fluctuations in relative prices.
} 
of allocations for the Home and Foreign agent $C_{t}, C_{t}^{*}, I_{t}, I_{t}^{*}, L_{t}, L_{t}^{*}, K_{t}, K_{t}^{*}, u_{t}, u_{t}^{*}, B_{H, t}, B_{H, t}^{*}$, $B_{F, t}^{*}$; and a collection of allocations for Home and Foreign final and intermediate good producers $Y_{t}, Y_{t}^{*}, C_{H, t}, C_{F, t}, C_{H, t}^{*}, C_{F, t}^{*}, I_{H, t}, I_{F, t}, I_{H, t}^{*}, I_{F, t}^{*}, N X_{t}$ satisfying (i) the optimality conditions of each agent; (ii) the optimality conditions of final and intermediate good producing firms; (iii) all markets clear; and (iv) the aggregate resource constraints of both countries.

\section{Numerical solution and calibration}

\subsection{The solution method}

To solve the model, we log-linearize the equilibrium conditions around a symmetric, deterministic steady state, where bond holdings are zero and the steady-state terms of trade is equal to $1 .{ }^{13}$

Letting a variable $\widehat{X}_{t}$ denote the percentage deviation of $X_{t}$ with respect to its steady state value $\bar{X}$, the linearized system yields an eight-dimensional system of difference equations:

$$
\left[\begin{array}{c}
\Gamma_{t+1} \\
\Lambda_{t+1}
\end{array}\right]=J\left[\begin{array}{c}
\Gamma_{t} \\
\Lambda_{t}
\end{array}\right]+V\left[\begin{array}{c}
\varepsilon_{t+1}^{z} \\
v_{t+1}
\end{array}\right],
$$

where $\Gamma_{t}=\left[\widehat{K}_{t}, \widehat{K}_{t}^{*}, \widetilde{B}_{H, t-1}, \widehat{Z}_{t}, \widehat{Z}_{t}^{*}\right]^{\prime}$ is the state vector, $\Lambda_{t}=\left[\widehat{C}_{t}, \widehat{C}_{t}^{*}, \widehat{T}_{t}\right]$ is the co-state vector, $\varepsilon_{t+1}^{z}$ is the $(2 \times 1)$ vector of technological shocks, and $v_{t+1}$ is the $(1 \times 1)$ vector of the sunspot or belief shock. ${ }^{14}$ The stability of the dynamic system (26) is determined by the number of eigenvalues of the coefficient matrix $J$ that lie inside the unit circle. If marginal cost is assumed to be decreasing in output (i.e., $\alpha+\gamma>1$ ), then the system (26) may not have a unique solution. In this case, the coefficient matrix $J$ can have more eigenvalues inside the unit circle than the number of predetermined variables $\left(\widehat{K}_{t}, \widehat{K}_{t}^{*}, \widetilde{B}_{H, t-1}, \widehat{Z}_{t}, \widehat{Z}_{t}^{*}\right)$, and consequently, multiple solutions to $(26)$ exist.

\footnotetext{
${ }^{13}$ In the steady state, the degree of increasing returns to scale can be expressed as the ratio between average and marginal costs, which is equal to the markup: i.e., $\frac{(\alpha+\gamma)(\bar{Y}+\phi)}{\bar{Y}}=\chi$. Consequently, for a steady state to exist, the steady-state markup cannot be lower than the degree of diminishing marginal cost i.e., $\chi \equiv \frac{\kappa}{\kappa-1} \geq \alpha+\gamma$.

${ }^{14}$ The variable $\widetilde{B}_{H, t}$ denotes the level deviation of bonds issued by the Home country from its steady state value, relative to steady-state Home consumption.
} 


\subsection{Parameterization}

The baseline parameter values used to compute the equilibrium are summarized in Table 1 . The U.S. is assumed to be the Home country and the rest of the world represents the Foreign country. As is standard in the literature, we set the time interval to be a quarter, the discount factor $\beta=0.99$, and the steady-state depreciation rate $\bar{\delta}=0.025$ (which implies $\eta \simeq 1.4$ ). The labor share in production is set equal to 0.7 and we set the inverse elasticity of labor supply $\nu=0$ (i.e., indivisible labor) to help generate indeterminacy for a small degree of returns to scale, a standard assumption of the indeterminacy literature (see, e.g., Benhabib and Farmer, 1994, 1996). The preference parameter $\psi$ is set so that in the steady state the agent in each country allocates one-third of their time to market activities. In the existing literature, the risk aversion parameter typically chosen lies between $1 \leq \sigma \leq 2$. Following Stockman and Tesar (1995), we set $\sigma=2$. In line with Benigno and Thoenissen (2008), we set the bond adjustment cost $\omega=0.001$ and the steady-state terms of trade equal to 1 . We set $a=b=0.88$ to ensure that the ratio of imports to GDP is equal to 0.12 , consistent with the U.S. economy.

Empirical studies offer no clear conclusion on the magnitude of the trade price elasticities, $\theta$ and $\rho$. As discussed by Corsetti et al. (2008a), estimates range from 0.1 to 2. Following Stockman and Tesar (1995), we initially set $\theta=\rho=1$ broadly consistent with the empirical estimate of Heathcote and Perri (2002). ${ }^{15}$ However, the robustness of the numerical results are examined for variations in these parameters. Specifically, following Backus et al. $(1994,1995)$ and Karabarbounis $(2014)$, we consider a higher parameterization by setting $\theta=\rho=1.5$. A low trade elasticity parameterization is also considered, where we set $\theta=\rho=0.5 .{ }^{16}$ This value is roughly consistent with the estimates of Anderton et al. (2004) and Corsetti et al. (2008a).

A key issue is to generate equilibrium indeterminacy with empirically plausible values for the steady-state markup $\chi$. Since intermediate firms use only capital and labor in the production process (6), this implies that the markup is value added. As discussed by Jaimovich (2007), value-added markups are estimated for the U.S. economy to lie between 1.2 to 1.4 . We set the steady-state markup $\chi=1.2$, consistent with the lower range of these empirical estimates. ${ }^{17}$ For the determinacy model, we assume that marginal costs are constant (i.e., $\alpha+\gamma=1$ ). In this case,

\footnotetext{
${ }_{15}^{15}$ Heathcote and Perri (2002) estimate the trade elasticity for the U.S. to be approximately 0.9.

${ }^{16}$ This value for the trade elasticity is not low enough that the model generates a negative international transmission mechanism á la Corsetti et al. (2008a).

${ }^{17}$ A sensitivity analysis was conducted using a higher value for the steady-state markup $\chi=1.3$ with little significant change in the results found.
} 
Table 1: Baseline parameter values

$\left.\begin{array}{lll}\hline \beta & 0.99 & \text { Discount factor } \\ \bar{\delta} & 0.025 & \text { Steady state depreciation rate of capital } \\ \nu & 0 & \text { Inverse elasticity of labor supply } \\ \sigma & 2 & \text { Inverse of the intertemporal substitution elasticity of consumption } \\ \theta & 1 & \text { Elasticity of substitution between home \& foreign consumption goods } \\ \rho & 1 & \text { Elasticity of substitution between home \& foreign investment goods } \\ a & 0.88 & \text { Home bias in consumption goods } \\ b & 0.88 & \text { Home bias in investment goods } \\ \omega & 0.001 & \text { Bond adjustment cost } \\ \bar{L} & 1 / 3 & \text { Steady state hours worked } \\ S_{L} & 0.7 & \text { Labor share in production } \\ \chi & 1.2 & \text { Steady state markup } \\ \alpha & 0.3 & \text { Elasticity of output with respect to capital } \\ \gamma & 0.7 & \text { Elasticity of output with respect to labor } \\ \alpha & 0.36 & \text { Elasticity of output with respect to capital } \\ \gamma & 0.84 & \text { Elasticity of output with respect to labor }\end{array}\right\}$ Determinacy model

with $\chi=1.2$ and $\phi>0$, there are zero average profits. For the indeterminacy model, we assume that marginal costs are declining in output (i.e., $\alpha+\gamma>1$ ). The numerical analysis suggests that under the baseline parameterization there are many values of $\alpha$ and $\gamma$ that generate indeterminacy for empirically plausible values of the steady-state markup. For simplicity, we follow Hornstein (1993) and set $\alpha+\gamma=\chi=1.2$, which implies that profits are not only zero on average but also in every period.

\subsection{Shock processes}

We calibrate the volatility of the shocks so as to minimize the distance between selected model moments and data moments. The objective function is computed as the sum of the squared differences between HP-filtered model moments and data moments, with the identity matrix as the weighting matrix. We check that the covariance matrix of the shocks that minimizes the objective function is positive semi-definite. ${ }^{18}$

Model moments are computed using frequency domain techniques as described in Uhlig (1999). The estimated sample moments for the data are taken from Gao et al. (2014) with the exception of the standard deviation and output correlation for real net exports and the first-order correlations

\footnotetext{
${ }^{18}$ In a small number of cases the estimated covariance matrix is not positive semi-definite. In these cases, we replace the estimated covariance matrix with its closest positive semi-definite matrix.
} 
for selected variables, which we computed using data from the Quarterly National Accounts of the OECD. Only the co-state variables $\widehat{C}_{t}, \widehat{C}_{t}^{*}, \widehat{T}_{t}$ of $(26)$ can be candidates for the sunspot shock $v_{t}$. We first consider a sunspot shock to $\widehat{T}_{t}$, where sunspots affect the forecast of the terms of trade: $\widehat{T}_{t}=E_{t-1} \widehat{T}_{t}+v_{t} .{ }^{19}$ Our approach is similar to the solution method of Farmer et al. (2015) in that we set the forecast error of the terms of trade as a new fundamental shock. In this way, we can treat the indeterminacy model as determinate and use the popular solution algorithm of Uhlig (1999) to obtain the solution.

As is standard, the log of technology in both countries is assumed to follow an $\mathrm{AR}(1)$ process with zero mean. In line with the IRBC literature, we assume that the productivity shocks in both the determinacy and indeterminacy models are quite persistent by setting the autocorrelation parameters $\zeta=\zeta^{*}=0.96$. In every alternative parameterization we keep $\zeta$ and $\zeta^{*}$ unchanged and we recalibrate the standard deviations and cross-country correlation of the shocks so as to minimize the distance between the chosen model and data moments.

Our choice of moments is as follows. In the determinacy model, we calibrate the standard deviations and the correlation of technology shocks so as to match the standard deviation of U.S. output and the correlation between U.S. and Foreign output. When only sunspot shocks are present in the indeterminacy model, the standard deviation of sunspot shocks are calibrated so as to match the standard deviation of U.S. output, which is common practice in the indeterminacy literature. On the other hand, as discussed by Donaldson et al. (2013), when both belief and technology shocks are simultaneously present there is no obvious way to estimate the individual variances of each shock or their correlation due to the lack of reliable empirical evidence. Consequently, we treat all standard deviations and correlations between the different shocks as free parameters and investigate how far indeterminacy can go in explaining the international macro puzzles. ${ }^{20}$ In this case, the covariance matrix of the indeterminacy model now has six free parameters: the standard deviations of the three shocks and the three shock cross-correlations. However, consistent with the empirical evidence of Backus et al. $(1992,1995)$, the cross-country correlation of technology shocks is restricted to be non-negative. The objective function is computed from the following eight moments: the standard deviations of output, the terms of trade, and net exports; the correlations with output of the terms of trade and net exports; the cross-country correlations of output and

${ }^{19}$ In an earlier version of this paper, we introduced the belief shock to Home consumption: $\widehat{C}_{t}=E_{t-1} \widehat{C}_{t}+v_{t}$ and obtained similar findings. These results are available from the authors on request.

${ }^{20}$ In this case, sunspot shocks can be correlated with fundamentals (they are no longer pure belief shocks) and the covariance matrix between technology and sunspot shocks can be interpreted as the coordination mechanism to revise expectations. 
consumption; and the correlation of the real exchange rate with relative consumption.

The estimated standard deviations and correlations used in the indeterminacy model with both sunspot and technology shocks are given in Table 3 of Section 4.2. The sunspot shock is positively correlated with the Home productivity shock and negatively correlated with the Foreign productivity shock. ${ }^{21}$ Furthermore, the quantitative exercise carried out implies that for both countries sunspot shocks are relatively greater in size than technology shocks. In the baseline calibration we find that the standard deviation of sunspot shocks relative to the standard deviation of technology shocks is 6.2. This finding is similar to Guo and Sturzenegger (1998), even though they use a different definition of sunspot shocks and a different methodology. They measure sunspot shocks using consumer sentiment data and find the standard deviation of sunspot shocks to be 6.7 times greater than the standard deviation of productivity shocks. ${ }^{22}$

\section{Results}

\subsection{The determinacy model and the international macro puzzles}

We start by presenting the main quantitative findings of the determinacy model, which will act as the benchmark for comparison. It is important to stress that with constant marginal costs and fixed capacity utilization the dynamics of the imperfect competition model behave very similar to standard IRBC models. ${ }^{23}$ In terms of the steady state, the output-capital ratio and consumptionoutput ratio are the same. The only difference relates to levels, where steady-state output is lower because of the presence of monopoly power, and thus steady-state capital is also lower. In terms of the log-linearized model, the only difference between the two model economies comes via the aggregate production technology condition:

$$
\widehat{Y}_{t}=\chi \alpha \widehat{K}_{t}+\chi \gamma \widehat{L}_{t}+\chi \widehat{Z}_{t}
$$

where under imperfect competition $\chi>1$. Thus, output fluctuations generated by technology shocks are amplified under imperfect competition.

\footnotetext{
${ }^{21}$ Therefore, a positive Home technology shock is often accompanied by an upward adjustment in the terms of trade forecast, whereas a positive Foreign technology shock is often accompanied by a downward adjustment.

${ }^{22}$ In our model, belief shocks have a relatively modest impact on the variables compared to technology shocks (see Figures 2 and 3 of Section 4.3). Consequently, the estimation procedure selects a relatively higher standard deviation for the sunspot shocks in order to match the selected moments.

${ }^{23}$ In standard IRBC models, $\chi=\alpha+\gamma=1$, given the absence of monopolistic competition.
} 
Using the parameter values summarized in Table 1, the unconditional second moments of the model is generated and compared against their empirical counterparts. Column 2 of Table 2 reports the estimated moments computed by Gao et al. (2014) for the period 1973(1) - 2007(4). ${ }^{24}$ The moments for real net exports and selected first-order autocorrelations are additionally estimated from the authors' own calculations. Columns $3-7$ of Table 2 report the predicted statistics of the determinacy model under different assumptions for the trade price elasticities and capacity utilization. In the baseline model, we first assume a fixed capacity utilization rate with unitary values for the trade elasticities $\theta=\rho=1$ (determinacy baseline). Secondly, we vary the trade elasticity parameters by either assuming $\theta=\rho=0.5$ or $\theta=\rho=1.5$. Thirdly, variable capacity utilization is introduced into the baseline model. Initially, we consider the implications of variable capacity utilization maintaining the assumption of constant marginal costs, so that increasing returns to scale arise only because of the fixed production cost. Next, we consider the implications when the model exhibits declining marginal costs but indeterminacy does not arise. For this case we set $\alpha+\gamma=1.099$, which is sufficiently small, relative to the steady-state markup $\chi=1.2$, to ensure equilibrium determinacy.

Comparison of columns 2 and 3 of Table 2 shows that the determinacy model suffers from the same well-established discrepancies with the data for international relative prices and quantities as standard IRBC models. While the data suggests that both the terms of trade and real net exports are counter-cyclical, the determinacy baseline counterfactually predicts that real net exports and the terms of trade are both pro-cyclical. Furthermore, a volatility puzzle arises where the predicted volatilities (relative to output) generated by the baseline model are significantly lower than the data. Simulated volatilities for real net exports (0.05), the real exchange rate (0.45), and the terms of trade (0.59) are all much smaller in comparison with the data. It is important to stress that the baseline model can generate sufficient volatility for consumption and employment. This is an important improvement from standard IRBC models and is due to the choice of GHH preferences. ${ }^{25}$ In the data, the cross-country correlation of output is greater than the cross-country correlation of consumption (0.58 vs. 0.43$)$, whereas the baseline model predicts the opposite. Finally, the baseline model suffers from the so-called Backus-Smith puzzle, where the model predicts a high

${ }^{24} \overline{\text { All series are logged, except real net exports, }}$ and Hodrick-Prescott filtered with a smoothing parameter of 1600. The statistics in Gao et al. (2014) are computed where the U.S. is taken as the Home country and the Foreign country is the aggregate of Canada, Japan, and 19 European countries.

${ }^{25}$ The ability of GHH preferences to generate higher consumption volatility arises because of the absence of an income effect on labor supply (see equation (16)). Consequently, output changes generate a stronger response of both employment and consumption. For further discussion see Raffo (2008). 
Table 2: Second moments of the determinacy model

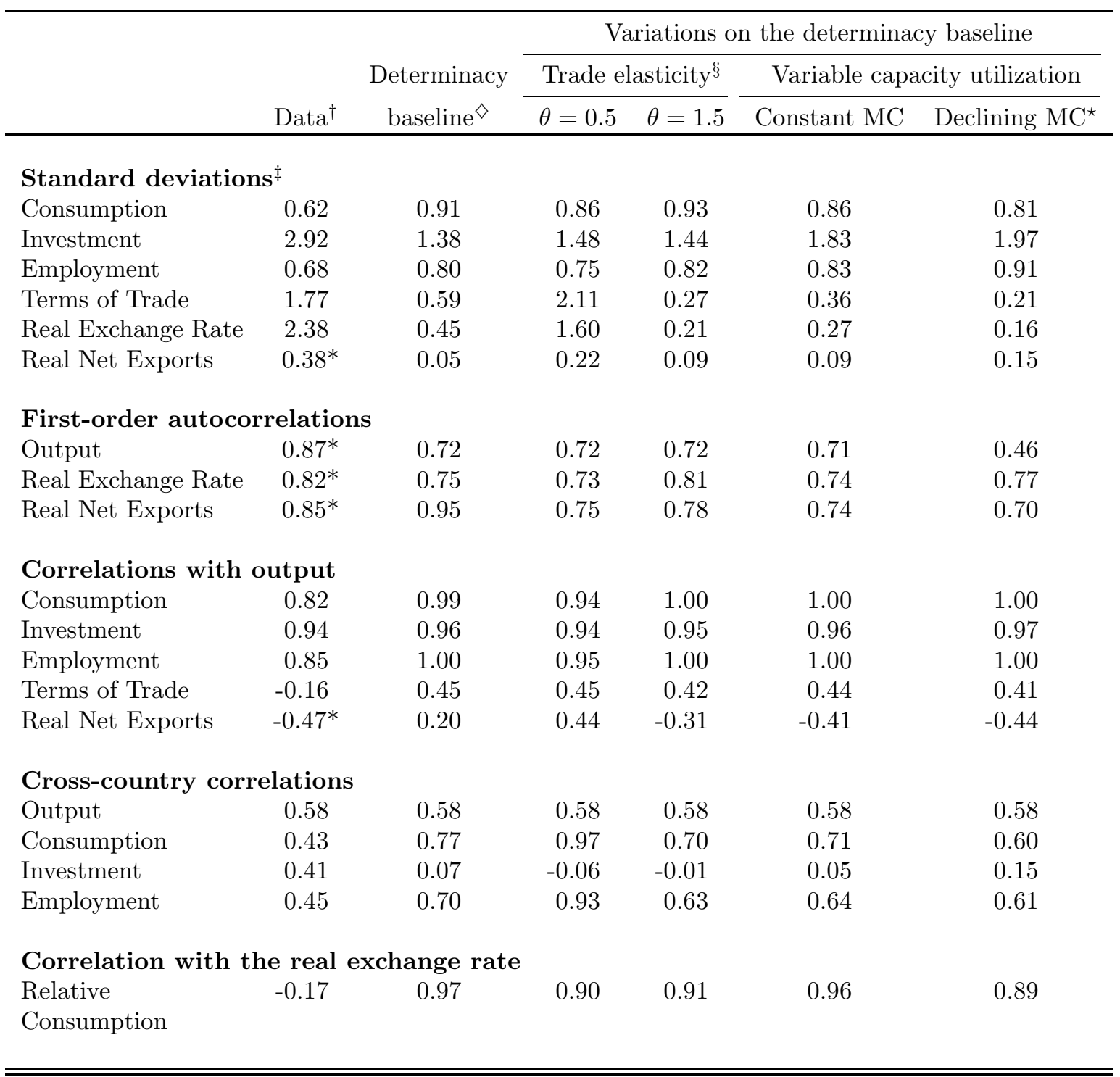

Notes:

$\dagger$ The estimated sample moments for the data are taken from Gao et al. (2014), except for values denoted by $*$ which are from the authors' own calculations.

$\diamond$ In the determinacy baseline, the standard deviations of Home and Foreign technology shocks are estimated to be 0.317 with a cross-country correlation of 0.315 . The autocorrelation parameters are set equal to $\zeta=\zeta^{*}=0.96$. In every alternative parameterization, we keep $\zeta$ and $\zeta^{*}$ unchanged and recalibrate the standard deviations and cross-country correlation of the shocks.

$\S$ For all variations in the trade price elasticities we set $\theta=\rho$.

$\star$ In the presence of declining marginal costs, we set $\alpha+\gamma=1.099$.

$\ddagger$ The standard deviations of all variables are divided by the standard deviation of output, except for the standard deviation of real net exports which is expressed in absolute terms. 
positive correlation between relative consumption and the real exchange rate (0.97), whereas in the data this correlation is negative $(-0.17)$.

By inspection of the final two columns of Table 2, the introduction of variable capacity utilization results in a negative correlation between net exports and output. In response to a positive Home technology shock, Home firms increase their capital utilization rate and the positive response of output is magnified, resulting in higher consumption and investment. The increased demand for Foreign investment goods is sufficiently strong to ensure that real net exports fall, hence generating the negative correlation with output. ${ }^{26}$

In terms of volatility, the performance of the model can be improved by choosing a lower value for the trade elasticity parameters $(\theta=\rho=0.5)$. From column 4 of Table 2 , this more than triples the volatilities of the terms of trade and the real exchange rate, and more than quadruples the volatility of real net exports relative to the determinacy baseline. Yet, despite these improvements, the model still generates less than 60 percent of the volatility observed for real net exports and less than 70 percent of the volatility observed for the real exchange rate. By setting $\theta=\rho=1.5$ (column 5 of Table 2), the model can generate counter-cyclical real net exports $(-0.31)$ almost matching the data. However, this is at the cost of further reducing the volatility of relative prices relative to the baseline. ${ }^{27}$ Therefore, similar to conventional IRBC models, the determinacy model faces an unpleasant trade-off. Relatively high trade elasticities can be selected to help generate counter-cyclical real net exports, or relatively low trade elasticities can be chosen to help improve the volatilities of real net exports and relative prices.

To understand this trade-off, Figure 1 reports selected impulse response functions for the Home country after a $1 \%$ positive technology shock. In each panel of Figure 1, the impulse responses are plotted under three alternative values for the trade price elasticity $\theta=\rho=0.5,1.0,1.5$. By inspection, the trade elasticity parameter crucially affects the response of the terms of trade after a productivity shock. If this parameter is relatively low, Home and Foreign goods are less substitutable for one another. Consequently, a positive technology shock results in a large deterioration in the terms of trade (i.e., a fall in the relative price of Home-produced goods) and a lower increase in domestic output. Hence, the lower the trade elasticities, the higher the volatility of international relative prices and the lower the volatility of output in response to productivity changes. Exports

\footnotetext{
${ }^{26} \mathrm{We}$ found that as long as the investment home bias parameter $b$ is greater than or equal to 0.77 , real net exports are always counter-cyclical in the variable capacity utilization model (correlation equal to -0.20 or lower). In this case, the choice of trade elasticities $\theta$ and $\rho$ have no effect on the sign of the correlation between real net exports and output.

${ }^{27}$ As shown by the final two columns of Table 2, allowing for variable capacity utilization has a similar effect.
} 

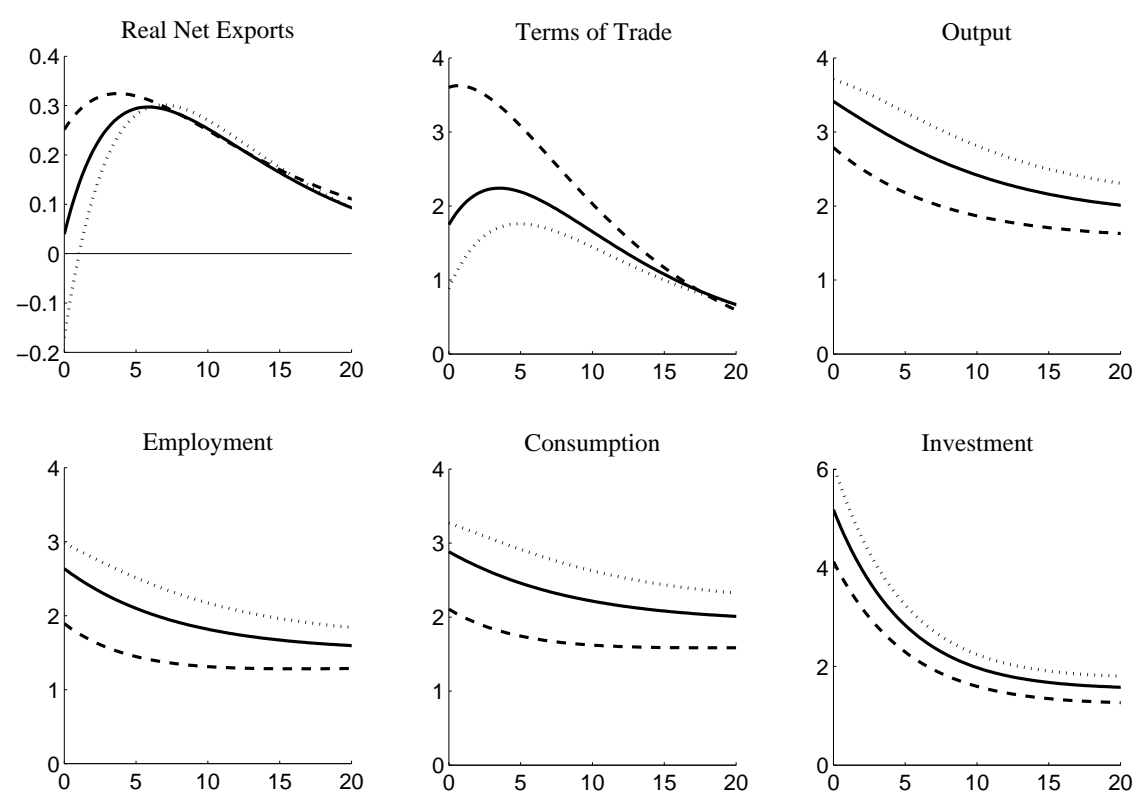

Figure 1: Dynamic responses for the determinacy model (Home country) to a positive $1 \%$ Home productivity shock: baseline (-); high trade elasticity $(\cdots)$; low trade elasticity (- - ). Vertical axes: $\%$ deviation from the steady state; Horizontal axes: years.

rise more than imports, and real net exports, in contrast to the data, are consequently pro-cyclical. With higher trade elasticities, productivity shocks will have a lower impact on relative prices and a higher impact on output, thereby generating counter-cyclical real net exports. Therefore, in order to match the volatility of relative prices and the correlation between real net exports and output, standard IRBC models require a negative international transmission mechanism whereby the terms of trade appreciate when domestic production expands. However, as shown by Thoenissen (2010), this negative transmission mechanism only arises under low values of the trade elasticities $\theta=\rho$ and for a very narrow range $0.4113 \leq \theta \leq 0.4678$.

\subsection{The indeterminacy model}

We now consider the indeterminacy model and present our main findings. For the parameter values given in Table 1 and the shock processes in Table 3, columns 4, 5, and 6 of Table 4 summarize the predicted statistics for the indeterminacy model given different assumptions for the trade elasticity parameter. In the indeterminacy baseline, we compute the model moments employing unitary values for the trade price elasticities $\theta=\rho=1$. Next, we consider $\theta=\rho=0.5$ and 
Table 3: Shock processes for the indeterminacy model

\begin{tabular}{lcccc}
\hline \hline & $\begin{array}{c}\text { Sunspot } \\
\text { shocks only }\end{array}$ & $\begin{array}{c}\text { Indeterminacy } \\
\text { baseline }\end{array}$ & \multicolumn{2}{c}{ Trade elasticity } \\
\cline { 5 - 6 } & & & $\theta=0.5$ & $\theta=1.24$ \\
\hline Technology shocks $\left(\varepsilon_{t}, \varepsilon_{t}^{*}\right)$ & & & & \\
s.d. of Home & - & 0.290 & 0.284 & 0.284 \\
s.d. of Foreign & - & 0.285 & 0.283 & 0.285 \\
autocorrelations & - & 0.960 & 0.960 & 0.960 \\
$\operatorname{corr}\left(\varepsilon_{t}, \varepsilon_{t}^{*}\right)$ & - & 0.001 & 0.001 & 0.000 \\
Sunspot shocks $\left(v_{t}\right)$ & & & & \\
s.d. & 0.832 & 1.798 & 1.744 & 1.772 \\
$\operatorname{corr}\left(\varepsilon_{t}, v_{t}\right)$ & - & 0.960 & 0.949 & 0.961 \\
$\operatorname{corr}\left(\varepsilon_{t}^{*}, v_{t}\right)$ & - & -0.112 & -0.092 & -0.133 \\
& & & & \\
\hline \hline
\end{tabular}

$\theta=\rho=1.24 .^{28}$ Column 3 of Table 4 reports the results for the indeterminacy model in the absence of intrinsic shocks (sunspot shocks only).

By comparing the indeterminacy baseline (column 4 of Table 4) against the traditional determinacy version (column 3 of Table 2), the indeterminacy model performs significantly better in terms of replicating some of the major features of the data. ${ }^{29}$ While both models can generate sufficient volatility for consumption and employment, the indeterminacy model can reproduce over $82 \%$ of the observed standard deviation of investment, a significant improvement on the baseline determinacy model which only generates $47 \%$ of the observed volatility. Similar to the data, both the terms of trade and the real exchange rate are more volatile than output in the indeterminacy model. In comparison with the determinacy baseline, the volatilities of both the terms of trade and the real exchange rate are increased by a factor of over 2.5. Indeed, the indeterminacy model can generate over $86 \%$ of the observed standard deviation of the terms of trade. However, despite these sizeable volatility improvements, the indeterminacy model still generates only half the volatility for the real exchange rate relative to the data. ${ }^{30}$ In terms of the volatility of real net exports, the indeterminacy model results in a standard deviation 13 times larger than the determinacy baseline, generating a significantly higher volatility than the data (0.65 vs. 0.38). By inspection of the final two columns of Table 4 , this is also true under alternative calibrations for the trade elasticities. ${ }^{31}$

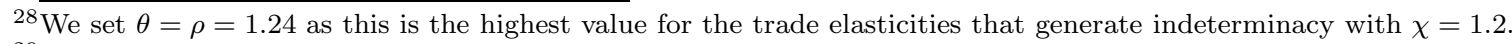
${ }^{29}$ The performance is also satisfactory for the moments we do not try to match directly.

${ }^{30}$ This is unsurprising given the assumption of the law of one price and the absence of non-traded goods, in our model the real exchange rate is a linear transformation of the terms of trade. See Corsetti et al. (2008a) for further discussion.

${ }^{31}$ In stark contrast to the determinacy model, a low trade elasticity is no longer associated with a significant improve-
} 
Table 4: Second moments of the indeterminacy model

\begin{tabular}{|c|c|c|c|c|c|}
\hline & \multirow[b]{3}{*}{ Data $^{\dagger}$} & \multirow{3}{*}{$\begin{array}{c}\text { Sunspot } \\
\text { shocks only }\end{array}$} & \multirow{3}{*}{$\begin{array}{c}\text { Indeterminacy } \\
\text { baseline }\end{array}$} & \multirow{2}{*}{\multicolumn{2}{|c|}{$\begin{array}{c}\text { Variations on } \\
\text { Indeterminacy baseline } \\
\text { Trade elasticity }{ }^{\S}\end{array}$}} \\
\hline & & & & & \\
\hline & & & & $\theta=0.5$ & $\theta=1.24^{\star}$ \\
\hline \multicolumn{6}{|c|}{ Standard deviations $\mathbf{s}^{\ddagger}$} \\
\hline Consumption & 0.62 & 0.81 & 0.93 & 0.92 & 0.92 \\
\hline Investment & 2.92 & 2.24 & 2.43 & 2.47 & 2.61 \\
\hline Employment & 0.68 & 0.91 & 1.04 & 1.03 & 1.03 \\
\hline Terms of Trade & 1.77 & 0.73 & 1.53 & 1.52 & 1.50 \\
\hline Real Exchange Rate & 2.38 & 0.56 & 1.17 & 1.15 & 1.14 \\
\hline Real Net Exports & $0.38^{*}$ & 0.17 & 0.65 & 0.60 & 0.72 \\
\hline \multicolumn{6}{|c|}{ First-order autocorrelations } \\
\hline Output & $0.87^{*}$ & 0.73 & 0.76 & 0.74 & 0.77 \\
\hline Real Exchange Rate & $0.82^{*}$ & 0.74 & 0.72 & 0.73 & 0.71 \\
\hline Real Net Exports & $0.85^{*}$ & 0.73 & 0.71 & 0.73 & 0.71 \\
\hline \multicolumn{6}{|c|}{ Correlations with output } \\
\hline Consumption & 0.82 & 1.00 & 0.99 & 0.99 & 0.99 \\
\hline Investment & 0.94 & 1.00 & 0.63 & 0.52 & 0.64 \\
\hline Employment & 0.85 & 1.00 & 0.99 & 0.99 & 0.99 \\
\hline Terms of Trade & -0.16 & 0.99 & -0.40 & -0.34 & -0.39 \\
\hline Real Net Exports & $-0.47^{*}$ & -0.97 & -0.22 & -0.09 & -0.25 \\
\hline \multicolumn{6}{|c|}{ Cross-country correlations } \\
\hline Output & 0.58 & -1.00 & 0.45 & 0.37 & 0.47 \\
\hline Consumption & 0.43 & -1.00 & 0.48 & 0.42 & 0.50 \\
\hline Investment & 0.41 & -1.00 & -0.50 & -0.69 & -0.43 \\
\hline Employment & 0.45 & -1.00 & 0.48 & 0.41 & 0.49 \\
\hline \multicolumn{6}{|c|}{ Correlation with the real exchange rate } \\
\hline Relative & -0.17 & 0.99 & 0.42 & 0.43 & 0.41 \\
\hline Consumption & & & & & \\
\hline
\end{tabular}

Notes:

$\dagger$ The estimated sample moments for the data are taken from Gao et al. (2014), except for values denoted by $*$ which are from the authors own calculations.

$\S$ For all variations in the trade price elasticities we set $\theta=\rho$.

${ }^{\star}$ We set $\theta=\rho=1.24$ as this is the highest value for which indeterminacy is possible.

¥ The standard deviations of all variables are divided by the standard deviation of output, except for the standard deviation of real net exports which is expressed in absolute terms.

ment in the volatility of real net exports and the terms of trade. 
In terms of output correlations, the indeterminacy model correctly predicts that real net exports and the terms of trade are both counter-cyclical. This finding is also robust to variations in the value of the trade elasticity, although under a low trade elasticity calibration the negative correlation between real net exports and output is low (-0.09). While the indeterminacy model struggles to generate cross-country output correlations higher than cross-country consumption correlations, it does much better than its determinate counterpart. The major weakness of the indeterminacy model relates to the correlation between the real exchange rate and relative consumption. Although the indeterminacy model predicts a significantly lower positive correlation relative to the determinacy baseline (0.42 vs. 0.97 ), this correlation remains counterfactual with the data where a negative correlation is observed. By inspection of the final two columns of Table 4, the positive correlation between the real exchange rate and relative consumption remains regardless of the choice of trade elasticity.

Overall, with the notable exception of the Backus-Smith puzzle, the indeterminacy model is able to solve several international relative price and quantity puzzles. Using a combination of a global extrinsic shock to the terms of trade and country-specific technology shocks, it can reproduce second moments for the terms of trade and real net exports that are both countercyclical and volatile over the cycle, and robust to variations in the trade elasticity parameter. It is important to highlight that the indeterminacy model performs poorly if sunspot shocks are the only source of aggregate fluctuations. Since the terms of trade are directly affected by sunspot shocks, by inspection of column 3 of Table 4, the indeterminacy model generates cross-country correlations which are equal to -1 . Therefore, with the exception of generating counter-cyclical real net exports, with only sunspot shocks the indeterminacy model is now unable to resolve any other major empirical irregularity of the data.

\subsection{Inspecting the mechanism}

To understand these results, Figure 2 depicts the impulse response functions after a one percent positive sunspot or belief shock, whereas Figure 3 depicts the impulse response functions after a one percent positive technology shock in the Home country. The dynamic responses after a Foreign technology shock are analogous to the dynamic responses after a Home technology shock.

An important element in understanding how sunspot and productivity shocks are transmitted in the indeterminacy model relates to the labor market. The log-linearized Home and Foreign 
labor demands can be expressed as:

$$
\begin{aligned}
& \widehat{w}_{t}=\left[\frac{\alpha(\eta-1)}{\eta-\alpha}\right] \widehat{K}_{t}+\left[\frac{\eta \gamma}{\eta-\alpha}-1\right] \widehat{L}_{t}-\left[\frac{(1-a) \eta}{\eta-\alpha}\right] \widehat{T}_{t}+\left[\frac{\eta}{\eta-\alpha}\right] \widehat{Z}_{t}, \\
& \widehat{w}_{t}^{*}=\left[\frac{\alpha(\eta-1)}{\eta-\alpha}\right] \widehat{K}_{t}^{*}+\left[\frac{\eta \gamma}{\eta-\alpha}-1\right] \widehat{L}_{t}^{*}+\left[\frac{(1-a) \eta}{\eta-\alpha}\right] \widehat{T}_{t}+\left[\frac{\eta}{\eta-\alpha}\right] \widehat{Z}_{t}^{*},
\end{aligned}
$$

where in our parameterization $\eta-\alpha>0$ and $\frac{\eta \gamma}{\eta-\alpha}-1>0$. With decreasing marginal costs, the source of indeterminacy arises from an upward-sloping aggregate labor demand schedule, which is steeper than the horizontal aggregate labor supply schedule (arising from an infinite elasticity of labor supply parameterization).

\subsubsection{The transmission mechanism of sunspot shocks}

In our model, a positive sunspot shock is a depreciation (increase) in the terms of trade. From equation (28), the upward-sloping Home aggregate labor demand schedule shifts down, increasing Home employment, which raises Home output and consumption. Consequently, sunspot shocks counterfactually generate a positive correlation between the terms of trade and output. As the demand for imports increases in the Home country due to higher consumption, real net exports decrease. For the Foreign country, from equation (29) the Foreign aggregate labor demand schedule shifts up, and as a result, Foreign employment decreases, reducing Foreign output and consumption. Therefore, absent all other shocks, Home and Foreign cross-correlations are all negative of magnitude -1 . Therefore, the international transmission mechanism of sunspots shocks suffers from the same limitations of the conventional, positive transmission of IRBC models: the data suggests that relative consumption increases in response to an appreciation of international relative prices, whereas sunspot shocks induce a positive correlation between relative consumption and international relative prices. Therefore, with the exception of generating counter-cyclical real net exports, the indeterminacy model using sunspot shocks alone cannot replicate the observed behavior for international relative prices and quantities or solve the Backus-Smith puzzle.

This finding is in stark contrast to the two-country, one-good models of Guo and Sturzenegger (1998) and Xiao (2004), where sunspot shocks result in positive cross-country correlations for consumption and output. In these models, shocks to the co-state variable stimulate global demand and increase production in both countries. For example, a sunspot-induced increase in domestic consumption, results in higher domestic output, and via an increase in imports, higher Foreign 

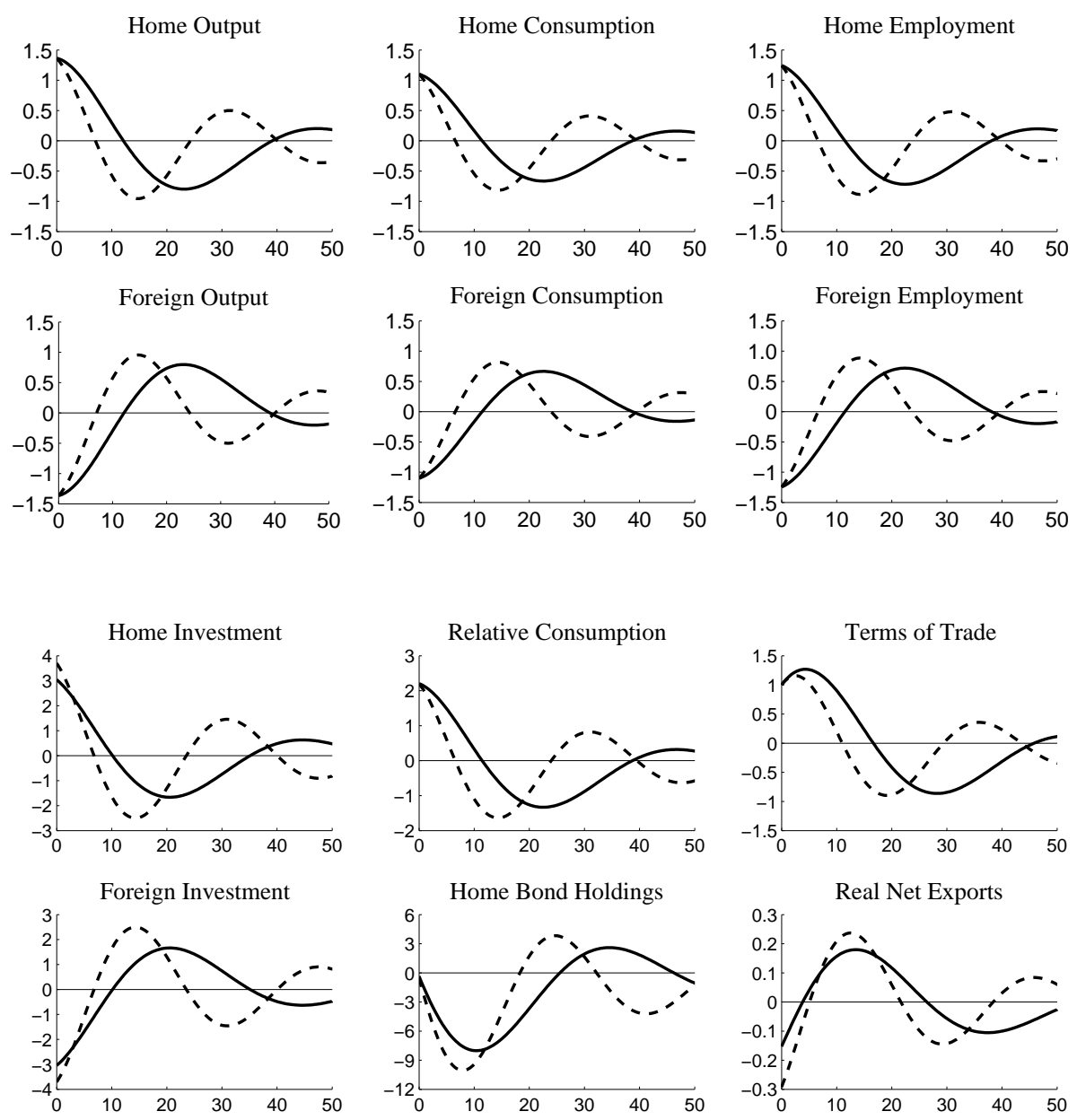

Figure 2: Dynamic responses for the indeterminacy model to a positive $1 \%$ sunspot shock: $\theta=$ $\rho=1(-)$ vs. $\theta=\rho=0.5(---)$. Vertical axes: $\%$ deviation from the steady state; Horizontal axes: years.

output. However, in our two-country, two-good model the terms of trade is an additional co-state variable. Now sunspot shocks are global extrinsic shocks that affect the terms of trade, inducing an output reallocation between the two countries. Consequently, cross-country correlations for consumption and output are negative.

\subsubsection{The transmission mechanism of productivity shocks}

Table 4 shows that the ability of the indeterminacy model to replicate several features of the data realistically depends on the inclusion of both sunspot and technology shocks. This arises because the propagation mechanism of productivity shocks is altered under indeterminacy. In standard 

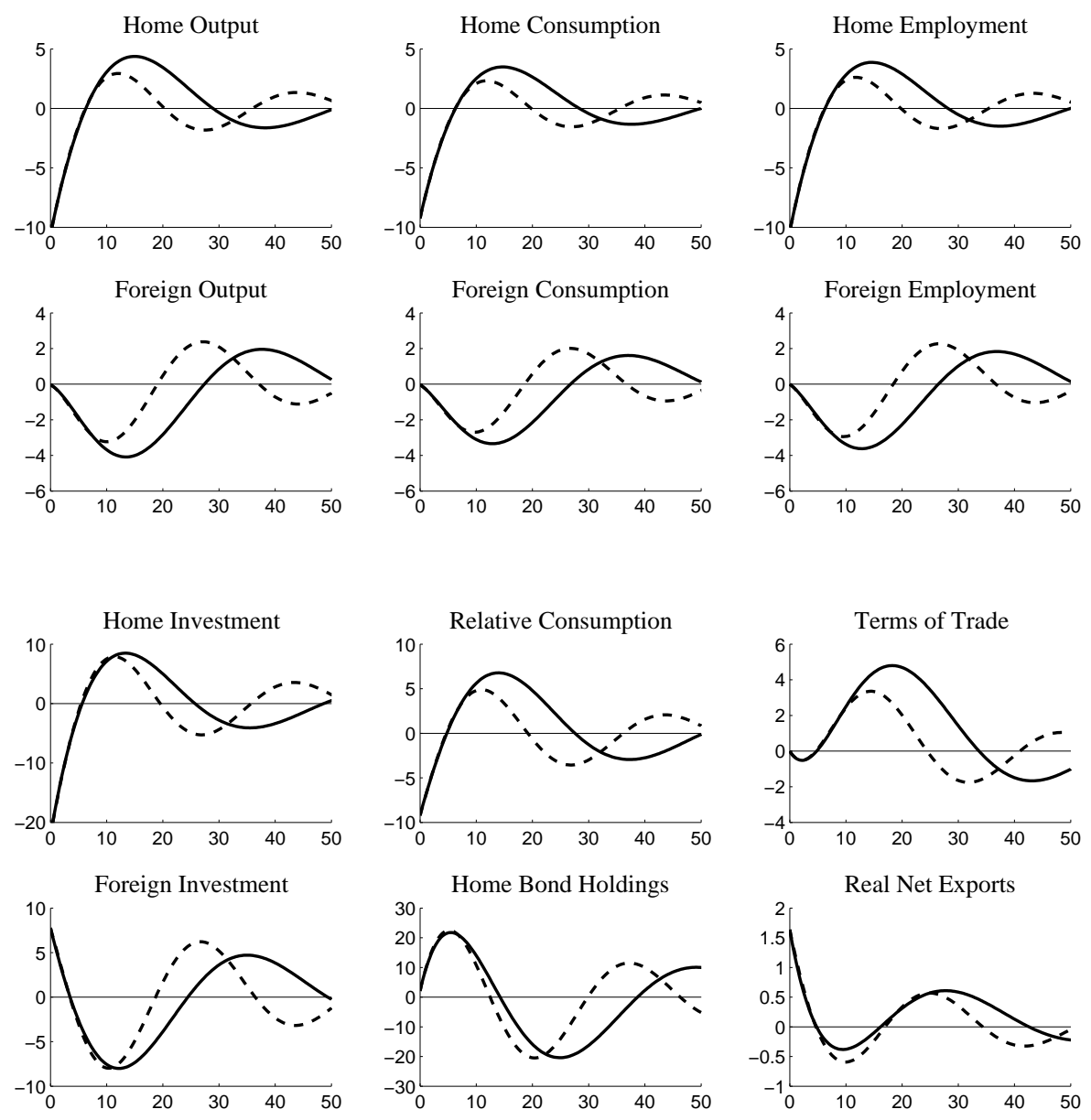

Figure 3: Dynamic responses for the indeterminacy model to a positive $1 \%$ Home productivity shock: $\theta=\rho=1(-)$ vs. $\theta=\rho=0.5(--)$. Vertical axes: $\%$ deviation from the steady state; Horizontal axes: years.

determinate IRBC models, provided the trade elasticity is high enough, a positive domestic technology shock causes a depreciation of the terms of trade (as Home prices decrease) and higher investment (as domestic investment goods are now relatively more productive). Global demand shifts towards the now relatively cheaper domestic goods resulting in an expansion of the domestic economy.

Now consider the transmission mechanism of a positive Home productivity shock under indeterminacy. From equation (28), an increase in $\widehat{Z}_{t}$ shifts the aggregate labor demand schedule inwards causing a fall in Home employment $\widehat{L}_{t}$ and consequently Home output. By inspection of the first row of Figure 3, the negative effect on Home output is sizeable but temporary. ${ }^{32}$ In the

\footnotetext{
32 The time it takes for Home output to rise above its pre-shock level depends on the bond adjustment cost parameter.
} 
Foreign country, the reduction in export demand due to lower Home consumption is exactly offset by the increase in investment, such that Foreign output is initially unchanged.

As shown in the third row of Figure 3, there is no contemporaneous adjustment in the terms of trade since it is predetermined. However, the subsequent adjustment of the terms of trade depends upon the behavior of Home marginal cost $\widehat{m c}_{t}$. In our model, there are two opposing effects on $\widehat{m c}_{t}$ from changes in $\widehat{Z}_{t}$. There is the standard effect of technology on marginal cost, whereby an increase in $\widehat{Z}_{t}$ directly reduces $\widehat{m c}_{t}$, which exerts downward pressure on domestic prices. Furthermore, in the presence of increasing returns to scale there is an additional effect, whereby $\widehat{m c}_{t}$ increases due to the fall in output, exerting upward pressure on domestic prices. By inspection of Figure 3, in the short-run the latter effect dominates the former (because of the large initial fall in output) resulting in a small appreciation of the terms of trade. After 10 quarters, the first effect becomes more important as output recovers, resulting in a gradual and significant depreciation of the terms of trade.

In summary, the indeterminacy model generates an unconventional transmission mechanism of productivity shocks, which arises due to the upward-sloping aggregate labor demand schedules. By inspection of Figure 3, we do not require low nor very specific trade elasticities to generate this transmission mechanism. The dynamics of the terms of trade predicted by our model is consistent with the empirical findings of Enders et al. (2011) for the U.S. economy. During the first few quarters after a positive technology shock, they find a small but significant appreciation of the terms of trade. However, in the medium-run, the terms of trade depreciates for an extended period of time, relative to its pre-shock level. The unconventional transmission mechanism that arises under indeterminacy is different to the negative international transmission mechanism à la Corsetti (2008a). In determinate IRBC models, by restricting the trade elasticities within a low and narrow range (see, e.g., Thoenissen, 2010) can lead to a downward-sloping world demand for domestic traded goods (with respect to the terms of trade) which results in a short-run appreciation of the terms of trade when Home production expands.

\subsubsection{Solving the volatility and output correlation puzzles}

The indeterminacy model can generate significant improvements in the volatilities of international relative prices and quantities. Compared to the baseline determinacy model, the volatility of the

In our baseline calibration, with a bond adjustment cost of 0.001 , Home output stays negative for 26 quarters. With a higher bond adjustment cost, e.g. 0.05, the time is reduced to 9 quarters. 
terms of trade and the real exchange rate are over 2.6 times greater, and the volatility of real net exports is 13 times greater in the baseline indeterminacy model. This improved performance is partly due to the degrees of freedom that our estimation procedure allows: when more than one shock occurs simultaneously the correlations between the innovations can be chosen so as to match the facts in the data. Nevertheless, the unconventional transmission mechanism of productivity shocks plays an even more important role in solving both the volatility and the output correlation puzzles. This is because the empirical success of the indeterminacy model would not be possible unless the transmission mechanism of technology shocks is sufficiently different from the transmission mechanism of sunspot shocks.

For example, notice from Figure 3 that after a positive Home technology shock there is very little correlation between the terms of trade and Home output in the short run. Because of this property, when a positive sunspot shock is combined with a positive Home technology shock the overall response of the terms of trade is increased, whereas the overall output response is reduced. Consequently, provided the correlation between these two shocks is high enough, and the standard deviation of the sunspot shock is sufficiently large (so that the overall response of output is mildly negative), the terms of trade will be volatile with respect to output and counter-cyclical.

A similar logic applies to the moments of real net exports. Notice from Figures 2 and 3 that each shock in isolation induces a negative correlation between real net exports and output. Because Home technology shocks and sunspot shocks are positively correlated, their combined impact ensures that the correlation between these two variables stays negative, and real net exports are sufficiently volatile with respect to output.

Finally by inspection of Table 4, in order to solve the volatility and output correlation puzzles we do not require low trade elasticities as emphasized by the existing IRBC literature. ${ }^{33}$ In our model, the trade elasticities only effect the magnitude of the peak and trough of the oscillatory impulse responses, as illustrated by Figures 2 and 3 .

\subsection{Solving the Backus-Smith puzzle with non-restricted cross-country productivity correlations}

The major discrepancy between the indeterminacy model and the data is that the model generates a positive correlation between the real exchange rate and relative consumption, whereas in the

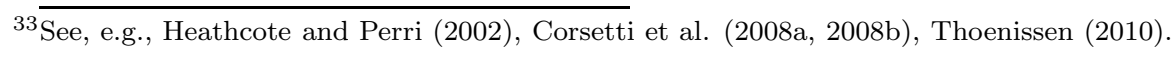


Table 5: Second moments of the indeterminacy model: unrestricted cross-country correlations for the productivity shocks, $\operatorname{corr}\left(\varepsilon_{t}, \varepsilon_{t}^{*}\right)$

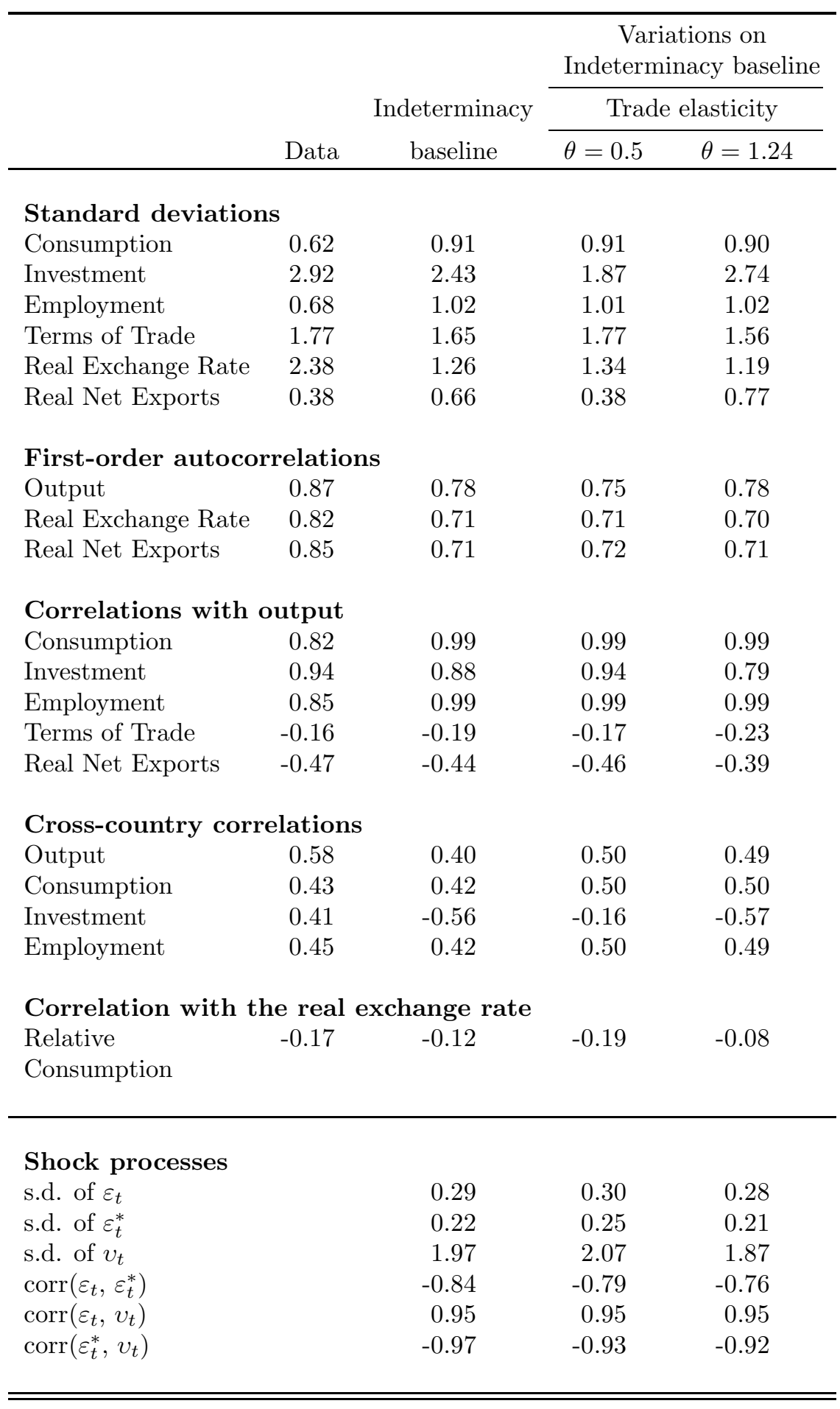

Notes: See Table 4 above. 
data this relationship is negative. From the impulse response functions given in Figures 2, sunspot shocks induce a positive correlation between relative consumption and the terms of trade (or real exchange rate). In the medium to long horizon, by inspection of Figure 3, productivity shocks also induce a strong positive correlation between these two variables. Therefore, if all shocks are positively correlated it is not possible to resolve the Backus-Smith puzzle in this model. This is exactly what happens in our estimated model. According to our estimated shock processes reported in Table 3, only the correlation between the Foreign productivity shock and the sunspot shock is negative, but not significantly. On the other hand, the correlation between the Home productivity shock and sunspot shock is very positive, and the correlation of Home and Foreign productivity shocks is close to zero.

In order to understand this mechanism further we re-estimate the shock properties without restricting the cross-country correlations for the productivity shocks to be non-negative. Table 5 summarizes the second moments and shock process estimated for this exercise. By inspection, the indeterminacy baseline can now generate a negative correlation between the real exchange rate and relative consumption $(-0.12)$ almost matching the data $(-0.17)$. This finding is robust to alternative calibrations for the trade elasticities and is not at the expense of any of the other international puzzles, which all continue to be solved. Intuitively, with only one global extrinsic shock, we crucially require that Home and Foreign technology shocks are strongly negatively correlated in order to introduce enough negative co-movement between the terms of trade and relative consumption. ${ }^{34}$ Therefore, despite a different propagation mechanism for productivity shocks than standard IRBC models, the indeterminacy model can only resolve the Backus-Smith puzzle under a negative cross-country correlation for productivity shocks.

\section{Conclusion}

Business cycle statistics suggest that both the terms of trade and real net exports are countercyclical and volatile. We have shown that by allowing for equilibrium indeterminacy, a combination of sunspot shocks and technology shocks can resolve these important features of the data. An unconventional transmission mechanism for productivity shock has been shown to play a crucial role in the empirical success of the model. This unconventional mechanism emerges from an

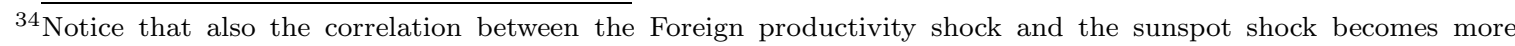
negative.
} 
upward-sloping aggregate labor demand schedule that arises under increasing returns to scale technology. This is different from the negative transmission mechanism of Corsetti et al. (2008a), which can occur by restricting the trade elasticity parameters within a low and narrow range. Therefore, this paper provides an alternative approach of solving the international macro puzzles based on indeterminacy rather than the values of the trade elasticity.

However, not all the puzzles can be solved in our model by jointly combining sunspot shocks and productivity shocks. In particular, the major failing of the indeterminacy model is its inability to replicate the negative correlation between the real exchange rate and relative consumption observed in the data. We have shown that in order to resolve the Backus-Smith puzzle, the model requires a strongly, negative cross-country correlation for technology shocks, which is not typical supported by the literature.

This result raises an interesting question as to whether other indeterminacy models could perform any better in resolving the Backus-Smith puzzle. Our analysis shows that in order to solve this puzzle the transmission mechanism of at least one shock must induce a negative comovement between the real exchange rate and relative consumption. This may be possible for alternative mechanisms that generate indeterminacy, for example without requiring increasing returns to scale. Such models could be successful in solving all the international macro puzzles, not only because of the degrees of freedom that are afforded by sunspot shocks, but because of the implied transformation of the transmission mechanism of technology shocks.

Alternatively, even indeterminacy models which rely on increasing returns may still be able to resolve all the puzzles by means of two sunspot shocks. In this case, the cross-country correlations for consumption and output will now depend on how these extrinsic shocks are related. Consequently, depending on the properties of the two sunspot shocks, it may be possible to generate a negative correlation between international relative prices and relative consumption. We leave this topic for future research. 


\section{References}

[1] Anderton, R., Di Mauro, F., Moneta, F., 2004. Understanding the Impact of the External Dimension on the Euro Area: Trade, Capital Flows and Other Macroeconomic Linkages. European Central Bank Occasional Paper no. 12.

[2] Backus, D. K., Kehoe, P. J., Kydland, F. E., 1992. International Real Business Cycles. Journal of Political Economy 100, 745-775.

[3] Backus, D. K., Kehoe, P. J., Kydland, F. E., 1994. Dynamics of the Trade Balance and the Terms of Trade: The J-Curve? American Economic Review 84, 84-103.

[4] Backus, D. K., Kehoe, P. J., Kydland, F. E., 1995. International Business Cycles: Theory and Evidence. In: T.F. Cooley (Ed.), Frontiers of Business Cycle Research, 331-356, Princeton University Press, Princeton, NJ.

[5] Backus, D. K., Smith, G., 1993. Consumption and Real Exchange Rates in Dynamic Economies with Non-Traded Goods.Journal of International Economics 35, 297-316.

[6] Benhabib, J., Farmer, R., 1994. Indeterminacy and Increasing Returns. Journal of Economic Theory 63, 19-41.

[7] Benhabib, J., Farmer, R., 1996. Indeterminacy and Sector-Specific Externalities. Journal of Monetary Economics 37, 421-443.

[8] Benhabib, J., Wen, Y., 2004. Indeterminacy, Aggregate Demand, and the Real Business Cycle. Journal of Monetary Economics 51, 503-530.

[9] Benigno, G., Thoenissen, C., 2008. Consumption and Real Exchange Rates with Incomplete Financial Markets and Non-Traded Goods. Journal of International Money and Finance 27, 926-948.

[10] Benigno, P., 2001. Price Stability with Imperfect Financial Integration. Mimeo, New York University.

[11] Boileau, M., 1999. Trade in Capital Goods and the Volatility of Net Exports and the Terms of Trade. Journal of International Economics 48, 347-365.

[12] Chari, V., Kehoe, P., McGrattan, E., 2002. Can Sticky Prices Generate Volatile and Persistent Real Exchange Rates? Review of Economic Studies 69, 633-663.

[13] Corsetti, G., Debola, L., Leduc, S., 2008a. International Risk Sharing and the Transmission of Productivity Shocks. Review of Economic Studies 75, 443-473.

[14] Corsetti, G., Debola, L., Leduc, S., 2008b. High Exchange-Rate Volatility and Low PassThrough. Journal of Monetary Economics 55, 1113-1128.

[15] Donaldson, J.B., Gershun, N., Giannoni, M.P., 2013. Some Unpleasant General Equilibrium Implications of Executive Incentive Compensation Contracts. Journal of Economic Theory $148,31-63$.

[16] Enders, Z., Muller, G. J., Scholl, A., 2011. How do Fiscal and Technology Shocks Affect Real Exchange Rates? New Evidence for the United States. Journal of International Economics 83, 53-69.

[17] Engel, C., Wang, J., 2011. International Trade in Durable Goods: Understanding Volatility, Cyclicality, and Elasticities. Journal of International Economics 83, 37-52. 
[18] Farmer, R., Guo, J., 1994. Real Business Cycles and the Animal Spirits Hypothesis. Journal of Economic Theory 63, 42-72.

[19] Farmer, R., Khramov, V., Nicolo, G., 2015. Solving and Estimating Indeterminate DSGE Models. Journal of Economic Dynamics and Control 54, 17-36.

[20] Gao, X., Hnatkovska, V., Marmer, V., 2014. Limited Participation in International Business Cycles Models: A Formal Evaluation. Journal of Economic Dynamics and Control 39, 255-272.

[21] Ghironi, F., 2006. Macroeconomic Interdependence under Incomplete Markets. Journal of International Economics 70, 428-450.

[22] Greenwood, J., Hercowitz, Z., Huffman, G., 1988. Investment, Capacity Utilization and the Real Business Cycle. American Economic Review 78, 402-417.

[23] Guo, J., Sturzenegger, F., 1998. Crazy Explanations of International Business Cycles. International Economic Review 39, 111-133.

[24] Heathcote, J., Perri, F., 2002. Financial Autarky and International Business Cycles. Journal of Monetary Economics 49, 601-627.

[25] Hornstein, A., 1993. Monopolistic Competition, Increasing Returns to Scale, and the Importance of Productivity Shocks. Journal of Monetary Economics 31, 299-316.

[26] Jaimovich, N., 2007. Firm Dynamics and Markup Variations: Implications for Sunspot Equilibria and Endogenous Economic Fluctuations. Journal of Economic Theory 137, 300-325.

[27] Karabarbounis, L., 2014. Home Production, Labor Wedges, and International Real Business Cycles. Journal of Monetary Economics 64, 68-84.

[28] Mendoza, E., 1995. The Terms of Trade, the Real Exchange Rate, and Economic Fluctuations. International Economic Review 36, 101-137.

[29] Raffo, A., 2008. Net Exports, Consumption Volatility and International Business Cycle Models. Journal of International Economics 75, 14-29.

[30] Raffo, A., 2010. Technology Shocks: Novel Implications for International Business Cycles. International Finance Discussion Paper No. 992, Board of Governors of the Federal Reserve System.

[31] Rotemberg, J., Woodford, M., 1996. Real Business Cycle Models and the Forecastable Movements in Output, Hours and Consumption. American Economic Review 86, 71-89.

[32] Schmitt-Grohe, S., 1997. Comparing Four Models of Aggregate Fluctuations due to SelfFulfilling Expectations. Journal of Economic Theory 72, 96-147.

[33] Schmitt-Grohe, S., 2000. Endogenous Business Cycles and the Dynamics of Output, Hours, and Consumption. American Economic Review 90, 1136-1159.

[34] Schmitt-Grohe, S., Uribe, M., 2003. Closing Small Open Economy Models. Journal of International Economics 61, 163-185.

[35] Stockman, A., Tesar, L., 1995. Tastes and Technology in a Two-country Model of the Business Cycle: Explaining International Comovements. American Economic Review 85, 168-185.

[36] Thoenissen, C., 2010. Exchange Rate Dynamics, Asset Market Structure and the Role of the Trade Elasticity. Macroeconomic Dynamics 15, 119-143. 
[37] Uhlig, H., 1999. A Toolkit for Analyzing Nonlinear Dynamic Stochastic Models Easily. In: Marimon, R., and Scott, A. (Eds.), Computational Methods for the Studies of Dynamic Economies, Oxford University Press, Oxford.

[38] Wen, Y., 1998. Capital Utilization under Increasing Returns to Scale. Journal of Economic Theory 81, 7-36.

[39] Xiao, W., 2004. Can Indeterminacy Resolve the Cross-Country Correlation Puzzle? Journal of Economic Dynamics and Control 28, 2341-2366. 